\title{
Transcriptional regulation and processing increase the functional variability of TRPM channels
}

Received: 21 December 2004 / Accepted: 19 February 2005 / Published online: 27 April 2005

(C) Springer-Verlag 2005

\begin{abstract}
Mammalian TRP channels display heterogenous biophysical properties and are involved in a variety of signal transduction pathways. To carry out their diverse biological functions and to adapt these functions to changes of the environment, mechanisms to regulate their molecular structure are required. Transcriptional regulation and post-transcriptional RNA processing represent essential instruments to generate TRP channel variants with modified properties. TRP variants are expressed depending on the tissue and developmental state. They can show distinct biophysical properties and mechanisms of activation, and thereby determine channel function and malfunction in certain human diseases. In this review, we give an overview of the variants of a given TRP gene, with the focus on the TRPM subfamily, and discuss their relevance with respect to their function under physiological and pathological conditions.
\end{abstract}

Keywords TRP channel variants · Transcriptional regulation $\cdot$ Promoter . Alternative splicing ·

Post-transcriptional processing $\cdot$ Transient receptor potential

\section{Introduction}

Transient receptor potential (TRP) channels were first described in Drosophila melanogaster as gene products involved in signal transduction of fly photoreceptors. The search for mammalian homologs of these proteins finally identified members of the classical (TRPC) subfamily and today we know at least 28 members of the TRP superfamily, subdivided into TRPC, melastatin-related (TRPM) and vanilloid receptor related (TRPV) channels (Montell et al. 2002). In addition, TRPA, mucolipins (TRPML) and poly-

\footnotetext{
A. Lis · U. Wissenbach · S. E. Philipp $(\bowtie)$

Institut für Experimentelle und Klinische Pharmakologie und Toxikologie, Medizinische Fakultät, Universität des Saarlandes, 66421 Homburg, Germany

e-mail: stephan.philipp@uniklinik-saarland.de

Tel.: +49-6841-1626152

Fax: +49-6841-1626402
}

cystins (TRPP) can be included. All TRP channels share structural similarity with six putative transmembrane segments (TM) and a predicted pore region between TM5 and TM6. Some amino acid motifs are well conserved throughout the superfamily whereas the overall amino acid sequence homology of distantly related TRP channels is rather low. Thus, it is no surprise that the mechanisms of activation, the ion permeation properties and the patterns of expression are quite diverse. Correspondingly, the biological functions of TRP channels are heterogeneous ranging from pain-perception, taste- and mechanosensation up to regulation of vasorelaxation. In the current view TRP proteins form tetrameric channel complexes and at least closely related members of one subfamily are capable to build heteromeric channels. By combinations of different TRP channel subunits, which build a common ion-conducting pore, the diversity of native TRP related channels may be widely increased.

The latter mechanism is not the only way how functional diversity of TRP channels can be accomplished. There is growing evidence that transcriptional regulation and alternative mRNA processing also contributes to the diversity of TRP channels. At present, variants have been described for a large number of TRP proteins. Most of them originate from alternative splicing (Table 1). TRP channel variants might be able to modulate functional properties of TRP channel complexes or to impair their functions. Accordingly, knowledge of these variants is essential, since they might provide mechanisms to adapt the properties of a given TRP channel to different functions and changes of the cellular environment. Furthermore, comparison of such variants may allow identification of structural domains essential for TRP function. This might be an advantage compared to synthetically generated mutants because the presence or absence of a specific part of the protein in a variant might define a naturally occurring phenotype. The biophysical and functional features of TRPM channels have been reviewed recently (Fleig and Penner 2004) and in an accompanying article of this issue (Harteneck 2005). In this review we now summarize what is currently known about splicing and transcriptional regulation of TRPM 
Table 1 Selected literature reporting alternative processing of TRPC, TRPV, and TRPM transcripts

Gene Reference

TRPC 1 (Sakura and Ashcroft 1997; Chang et al. 1997; Wang et al. 1999; den Dekker et al. 2001; Yang et al. 2002; Antoniotti et al. 2002)

TRPC 2 (Berg et al. 1997; Wissenbach et al. 1998; Vannier et al. 1999; Hofmann et al. 2000; Chu et al. 2002, 2004; Yildirim et al. 2003)

TRPC 3 (Ohki et al. 2000; Yang et al. 2002)

TRPC 4 (Freichel et al. 1998; Walker et al. 2001, 2002; Mery et al. 2001; Schaefer et al. 2002; Yang et al. 2002; Qian et al. 2002; Satoh et al. 2002)

TRPC 6 (Philipp et al. 2000; Zhang and Saffen 2001)

TRPC 7 (Walker et al. 2001)

TRPV1* (Schumacher et al. 2000; Sanchez et al. 2001; Xue et al. 2001; Wang et al. 2004)

TRPM1 (Fang and Setaluri 2000; Xu et al. 2001; Zhiqi et al. 2004); this manuscript

TRPM2 (Wehage et al. 2002; Zhang et al. 2003a)

TRPM3 (Lee et al. 2003)

TRPM4 (Launay et al. 2002; Nilius et al. 2003; Murakami et al. 2003)

TRPM5 (Prawitt et al. 2000)

TRPM6 (Schlingmann et al. 2002; Walder et al. 2002; Chubanov et al. 2004)

TRPM8 This manuscript

*For a comparison of TRPV1 splice variants see review by

B. Niemeyer (2005)

channels and supplement the published data by unpublished observations obtained in our lab.

\section{Materials and methods}

Northern blots Five to ten micrograms of polyA ${ }^{+}-\mathrm{RNA}$ were hybridized under stringent conditions to $\left[\alpha^{32} \mathrm{P}\right] \mathrm{dCTP}-$ labeled cDNA fragments of TRPM1-Long (nucleotides 11,325 and nucleotides $3,350-5,030$ ) or to a 230 -bp fragment encoding amino acid residues $\mathrm{Glu}^{637}$ to $\mathrm{Arg}^{713}$ of TRPM8a (Acc. no Q7Z2W7). The filters were exposed to X-ray film with intensifying screens for 21 days and hybridized again with a 239 bp cDNA fragment of the human glyceraldehyde-3-phosphate dehydrogenase (GAPDH) as control.

Cloning of TRPM1 splice variants Oligonucleotide primers up1 (rat/mouse: 5'TCC TTC TGA GCT GAC TGA GCC), up 2 (rat/mouse: 5'GCG GGA CCA GCT TCT AGT TAC), down 1 (rat/mouse: 5'GGG CCA AAG ACG AAG ATC TGG) and down 2 (rat: 5'CCA TTA GCA TTC AGT TTC CGG G; mouse: 5'CAT CAG CAC TCA GTT TCC GCG) were used to amplify mouse and rat cDNA fragments after oligo $\mathrm{dT}_{(18)}$ primed reverse transcription of total RNA from mouse or rat brain. For amplification we used the Long expand PCR Kit (Roche, Mannheim, Germany) and the following conditions: $2 \mathrm{~min}$ at $94^{\circ} \mathrm{C}, 10$ cycles $\left(94^{\circ} \mathrm{C}, 10 \mathrm{~s}\right.$; $\left.62^{\circ} \mathrm{C}, 30 \mathrm{~s} ; 68^{\circ} \mathrm{C}, 5 \mathrm{~min}\right), 25$ cycles $\left(94^{\circ} \mathrm{C}, 10 \mathrm{~s} ; 62^{\circ} \mathrm{C}, 30 \mathrm{~s}\right.$; $68^{\circ} \mathrm{C}, 5 \mathrm{~min}+20 \mathrm{~s} /$ cycle) and $7 \mathrm{~min}$ at $68^{\circ} \mathrm{C}$. Fragments were subcloned and sequenced on both strands. The number of clones analysed are indicated in Fig. 2.

Cloning of TRPM8 splice variants Oligonucleotide primers 5'ATG AAA TCC TTC CTT CCT GTC and 5'TTA TTT GAT TTT ATT AGC AAT CTC TTT CAG were used to amplify human cDNA fragments after oligo $\mathrm{dT}_{(18)}$ primed reverse transcription of RNA obtained from prostate cancer tissues (stage pT3b) of four patients. Fragments were amplified and subcloned using the following conditions: $2 \mathrm{~min}$ at $94^{\circ} \mathrm{C}, 35$ cycles $\left(94^{\circ} \mathrm{C}, 30 \mathrm{~s} ; 58^{\circ} \mathrm{C}, 30 \mathrm{~s} ; 72^{\circ} \mathrm{C}, 4 \mathrm{~min}\right)$ and $10 \mathrm{~min}$ at $72^{\circ} \mathrm{C}$. Five independent clones were sequenced on both strands.

\section{TRPM1}

Melastatin (TRPM1, MLSN) is the founding member of the TRPM family. Its first initial was chosen to rename all eight relatives "TRPM" (Montell et al. 2002). Although it was the first TRPM to be cloned, there are no published reports about its biophysical properties. Originally, it has been identified by differential cDNA display in mouse B16 melanoma cell lines in search for genes whose expression correlates with the aggressive metastatic behavior of the cells (Duncan et al. 1998). A 2,722 bp transcript encoding 542 amino acid residues (aa) was cloned (see Fig. 2c), which was highly expressed in poorly metastatic cells but strongly reduced in a highly metastatic line. This correlation suggested that this protein may serve as a tumor suppressor protein but this idea could not be further substantiated. Nevertheless, TRPM1 may have clinical importance since down-regulation of TRPM1 mRNA in primary cutaneous tumors may serve as a prognostic indicator in patients with melanoma (Deeds et al. 2000; Duncan et al. 2001; Miller et al. 2004). The TRPM1 mouse variant was initially not recognized as member of the TRP family since it included only the aminoterminal part of a TRP protein and lacked a transmembrane region and the characteristic "Trp"- domain (see Fig. 2c). However, a human ortholog with 1,533 amino acids in length (Gene accession no. AF071787) was identified in a hybridization screen of a retinal cDNA library (Hunter et al. 1998; see Fig. 2c). The human and mouse genes map to chromosome 15q13-q14 and to chromosome 7 , respectively, and show a similar organization (see Fig. 2a). The mouse gene was reported to consist of 27 exons with the initiation codon in exon 3 located 345 nucleotides downstream of the transcription start site (Hunter et al. 1998). However, this 5 ' untranslated region shows sequence homology to other TRPM coding sequences suggesting that additional exons might exist, which may encode an expanded TRPM1 amino terminus. Exon 14 is the final exon in the mouse 2,722 bp transcript and so far no mouse transcripts that correspond to the longer human form have been isolated. Directly upstream of the transcription initiation site a proximal promoter region (see Fig. 2a) contains transcriptional regulatory elements unique to genes 
with restricted melanocytic expression pattern (Hunter et al. 1998; Miller et al. 2004; Zhiqi et al. 2004). This promoter is capable to drive reporter gene expression in mouse and human melanoma cells. Recently, it could be shown that MITF is an essential transcription factor for melanocytic development and a major transcriptional regulator of TRPM1 expression through its interaction within the proximal promoter region (Miller et al. 2004; Zhiqi et al. 2004). RT-PCR analysis of mouse (Duncan et al. 1998) and Northern blots of rat tissues (Fig. 1) revealed TRPM1 transcripts in eye and melanoma cells but failed to detect transcripts in lung, heart, liver, spleen, kidney and intestine. Additionally, long TRPM1 transcripts seem to be expressed in human B- and T-cell lines and in monocytes (Perraud et al. 2004). Northern blot analysis of pigmented human SK-MEL-19 and 23c22 melanocytes showed a variety of long $(5.4 \mathrm{~kb})$ and short $(1.3,1.8$, and $4.0 \mathrm{~kb})$ transcripts, whose expression was upregulated after induction of cell differentiation (Fang and Setaluri 2000). In addition, transcripts of $0.8,1.7,2.3$, and $>3.0 \mathrm{~kb}$ were generated constitutively by alternative splicing and may include $3^{\prime}$ terminal exons. Thus, multiple transcripts were generated and it has been suggested that TRPM1 expression can be regulated at the level of both transcription and mRNA processing (Fang and Setaluri 2000). The inducible short transcripts were predicted to encode short human TRPM1 variants (MLSN-S) of 500 amino acids which - similar to the 542 aa mouse melastatin - include only the N-terminal segment but lack any transmembrane domain of the long

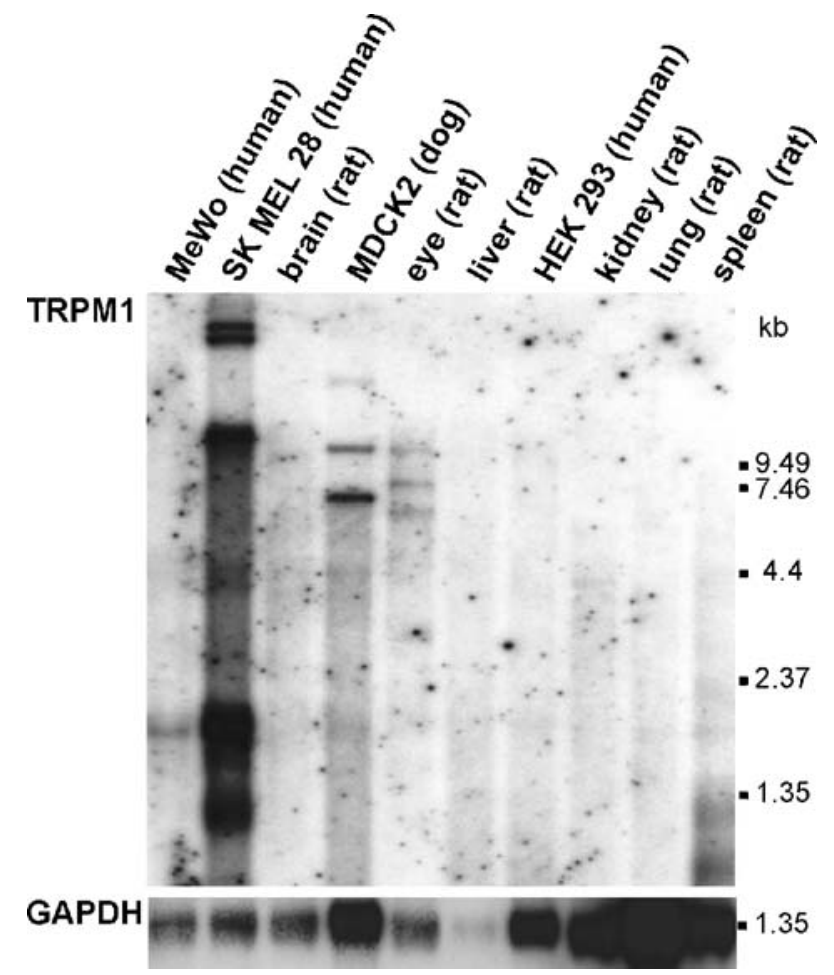

Fig. 1 TRPM1 transcripts of different length are expressed in human, rat, and $\operatorname{dog}$ tissues. PolyA ${ }^{+}$-RNA was hybridized to labeled cDNA fragments of TRPM1-Long (upper panel). The lower panel shows a control hybridization of the same blot with the glyceraldehyde-3phosphate dehydrogenase (GAPDH) cDNA.
(1,533 aa) TRPM1 protein (MLSN-L). Although such short variants have never been identified in human tissues, this prediction inspired the idea that MLSN-S may represent a cytoplasmic isoform, which regulates MLSN-L (Xu et al. 2001). It has been shown that overexpression of 500 aminoterminal amino acids of TRPM1 altered the membrane localization of the long variant presumably by direct interaction of the two variants. In addition, MLSN-S seemed to suppress MLSN-L mediated $\mathrm{Ca}^{2+}$ entry. Therefore, it has been hypothesized that control of translocation through interaction between MLSN-S and MLSN-L represents a mode for regulating ion channel activity (Xu et al. 2001).

TRPM1 transcripts are expressed in several human melanocytic lines (Fig. 1). Whereas short transcripts of $\sim 1.3$ and $\sim 1.8 \mathrm{~kb}$ and transcripts larger than $10 \mathrm{~kb}$ are present in SK-MEL-28 cells only a $\sim 1.8 \mathrm{~kb}$ mRNA is abundant in MeWo cells. These patterns differ to those described for human SK-MEL-19 and SK-MEL-23c22 melanocytes (Fang and Setaluri 2000), indicating that alternative splicing of TRPM1 strongly depends on the cell subtype. In addition, we found TRPM1 mRNA of $\sim 6.5, \sim 8.0$ and $\sim 10$ $\mathrm{kb}$ in rat eye were it may be abundant in the pigmented epithelium of the retina. Finally, large TRPM1 transcripts are expressed $(\sim 7 \mathrm{~kb}, \sim 10 \mathrm{~kb},>12 \mathrm{~kb})$ in kidney epithelial cells from dog (MDCK2) but not in human embryonic kidney cells (HEK-293) showing that its expression is not limited to pigmented epithelial cells from skin and eye.

By database analysis we identified a new TRPM1 transcript cloned from a mouse retinal library (Acc no. AK044507). As shown in Fig. 2c this 2,008 nt mRNA is predicted to encode 461 amino acids with overlapping sequence homology to mouse and human melastatin but extending these sequences at the aminoterminal end by 116 amino acid residues. Just as the whole TRPM1 gene, the coding nucleotides are well conserved in the mouse and human genes and in the rat gene, which is located on chromosome 1q22 and consists of 28 exons (Fig. 2a). The additional 116 amino acid residues are encoded by an additional exon 1a and by exons 2 and 3. Exons 2 and 3 are non-coding in mouse and human melastatin sequences when they are expressed from the proximal promoter (Fig. 2a). Exon 1a is located $\sim 33.5 \mathrm{~K}$ upstream to a region homologous to the human and mouse proximal promoter (AF 084519) which is responsible for TRPM1 expression in melanocytes. We suggest that a second distal promoter may exist, which drives expression of aminoterminal extended variants of TRPM1. Using a RTPCR based strategy (Fig. 2b) and primer up1 deduced from the genomic sequence upstream of the initiation codon of AK044507 in combination with primer down1 located in exon 10, we cloned cDNA fragments from mouse brain and eye which confirmed the sequence of AK044507. Using primer up1 in combination with primer down2, which is located at a position corresponding to the translation stop of human MLSN (AF071787), we failed to amplify cDNA fragments longer than $\sim 2,200 \mathrm{bp}$. We suppose that secondary mRNA structures may inhibit reverse transcription of longer transcripts. However cloning of these 2,200-bp amplification products identified a new TRPM1 variant from mouse called TRPM1 ${ }_{\Delta 189-1,078}$ (Fig. 2b, c). In this variant 

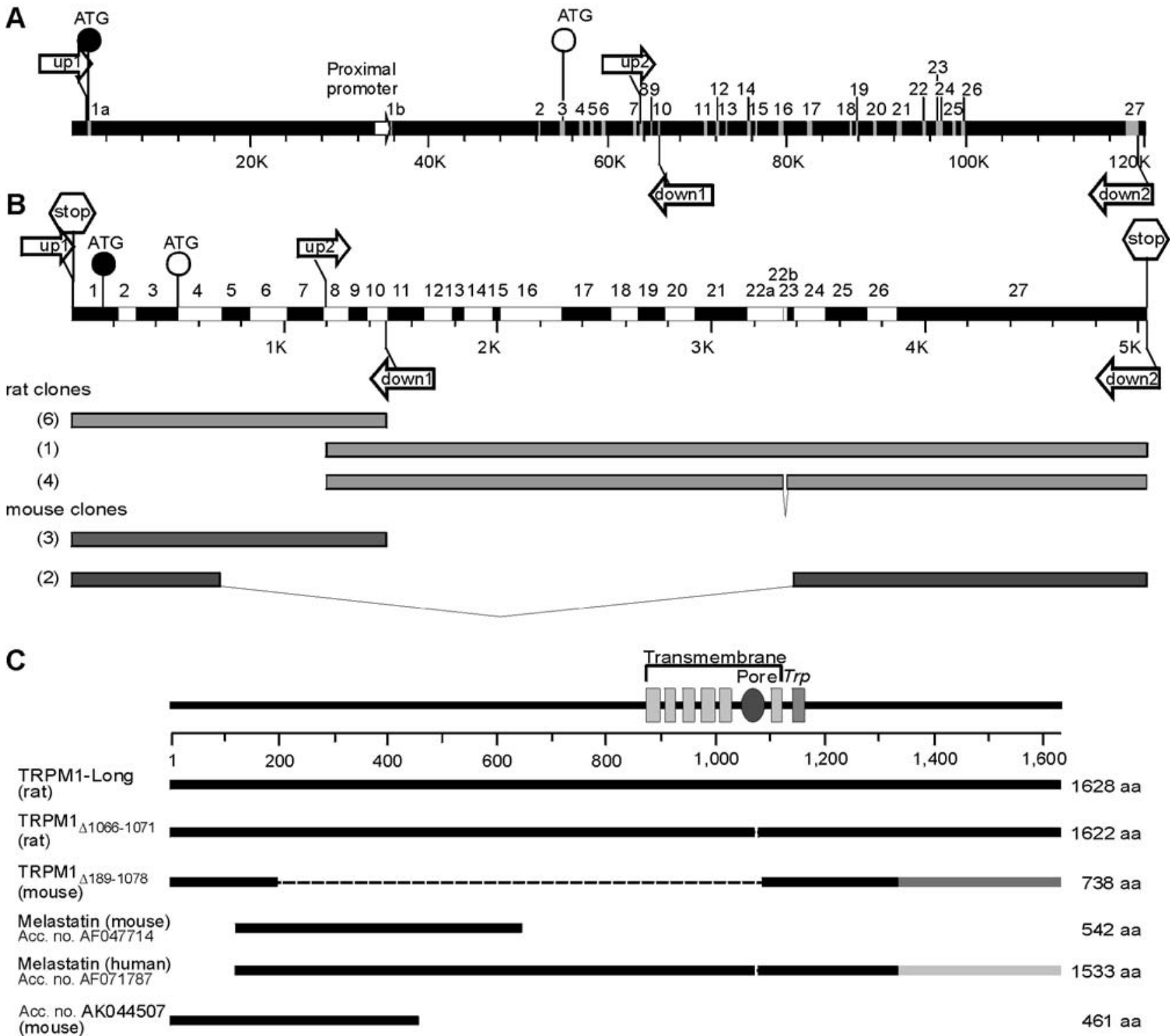

Fig. 2 Identification of TRPM1 splice variants. a Scheme of the rat TRPM1 gene consisting of 28 exons (gray boxes), highly similar to the mouse and human genes. Splice donor and splice acceptor sites are invariant in all intervening intron sequences (black boxes). As in b, the location of an initiation codon ( $A T G)$ corresponding to mouse and human melastatin (AF047714 and AF071787) is indicated by an open circle. A hollow arrow marks a region homologous to the human and mouse proximal promoter (AF084519). This promoter is $5^{\prime}$ flanking to exon $1 \mathrm{~b}$ present in the mouse and human melastatin mRNA (AF047714, AF071787) shown in c. An additional start ATG (closed circle) present in the alternative exon 1a of AK044507 (c) and of the obtained rat and mouse clones shown in $\mathbf{b}$ is located 33.5 K upstream. Just as in b, positions of primers up 1, up2, down1, and down 2 used to amplify mouse and rat cDNA (b) are indicated.

exon 4 is spliced to exon 24. It spans a reading frame of 738 amino acid residues. Similar to AK044507 it contains 116 additional residues at the aminoterminus as well as carboxyterminal end homologous to the human variant AF047714 (Fig. 2c). This new variant indicates that also in mouse tissues carboxyterminal extended TRPM1 variants are expressed. b Cloning strategy of rat (light gray bars) and mouse (dark gray bars) TRPM1 cDNAs. Number of clones sequenced as indicated in parentheses. Stop codons in frame are shown. In two mouse clones exon 4 is spliced to exon 24 . In one rat clone splicing to an alternative splice donor site within exon 22 leads to the extension of exon 22 by 18 nucleotides (exon 22b). c Scheme of different TRPM1 splice variants from rat, mouse, and human with 461-1,628 amino acids $(a a)$ in length. Black bars represent regions with $>90 \%$, dark gray bars with $80-90 \%$, and light gray bars with $50-60 \%$ sequence identity. Dotted lines indicate missing domains compared with TRPM1-Long. Sequences of TRPM1-Long, TRPM1 ${ }_{\Delta 1066-1071}$, and TRPM1 $1_{\Delta 189-1078}$ have been deposited in the GeneBank database. $\operatorname{Trp}$ TRP domain.

With the primer combinations up1/down1 and up2/ down2 we amplified overlapping cDNA fragments from rat brain and eye (Fig. 2a, b). The predicted new TRPM1 splice variant TRPM1-Long (TRPM1-L) contains 1,628 amino acid residues. A stop codon upstream and in frame of the initiation codon (Fig. 2b) indicates that the reading frame is complete. Apart from the extended aminoterminal end, this 
variant is highly homologous to human and mouse sequences with more than $90 \%$ amino acid sequence identity (black bars in Fig. 2c). However, the last 300 amino acid residues show considerable sequence divergence, unexpected for orthologous proteins. Whereas mouse and rat sequences are $89 \%$ identical within this region (dark gray bars in Fig. 2c), the human sequence shows only $\sim 50 \%$ identity (light grey bars in Fig. 2c) and several additional short sequence insertions (not shown), indicating that in this region alternative splicing may occur, too. TRPM1-L contains six additional amino acid residues compared to a further identified variant, called TRPM1 $1_{\Delta 1,066-1,071}$ (Fig. 2b, c) and compared to the human variant AF071787. Their presence arise by the usage of an alternative splice donor site within the intron between exon 22 and exon 23 leading to an extended exon $22 \mathrm{~b}$. Interestingly, these residues are located within the putative pore region of TRPM1. This finding may have special importance, since it may designate alternative splicing as a mechanism to adapt the permeation properties of the channel. We do not know the physiological significance of the new variants. However our findings may be a step forward to understand TRPM1 channels and might explain, why there is only little known about the functional properties of this first identified member of the TRPM subfamily.

\section{TRPM2}

The TRPM2 gene (LTRPC2) was originally identified on human chromosome $21 \mathrm{q} 22.3$ within a region which is linked to a variety of human genetic disorders (Nagamine et al. 1998). However, the hope to identify a gene which is linked to a human disease has not yet been fulfilled. When overexpressed in HEK-293 cells the TRPM2 cDNA encodes non-selective cation channels of 1,503 amino acids which can be activated by ADP-ribose, $\beta$-NAD or $\mathrm{H}_{2} \mathrm{O}_{2}$ (Perraud et al. 2001; Sano et al. 2001; Hara et al. 2002). TRPM2 is unique for its C-terminal NudT9-homology domain (NudT9-H) which shows considerable homology to NudT9 ADP-ribose hydrolase (ADPRase). This domain has been shown to be essential for channel activation by ADPribose (Perraud et al. 2001). The channel is thought to be involved in pathways which respond to oxidants and might play a role as a $\mathrm{Ca}^{2+}$ permeable channel that mediates celldeath induced by oxidative stress. Comprehensive reviews about the structure and function of TRPM2 (Perraud et al. 2003 ) and their potential role in immune cells (Perraud et al. 2004) have been published recently. Furthermore, a review on the regulation of TRPM2 channels in neutrophil granulocytes by ADP-ribose is included in this issue (Heiner et al. 2005).

Northern blots unmasked TRPM2 transcripts of different length in human brain areas (Nagamine et al. 1998) and in mouse spleen (Hara et al. 2002). Amplification of two adjacent cDNA segments from HL-60 neutrophils identified two alternative splice events (Wehage et al. 2002). Splicing internal to exon 11 led to the absence of amino acid residues 538-557 within the aminoterminus and skipping of exon 27 was connected to the loss of residues 1,292-1,325 within the carboxyterminus of the protein. Additionally, two amino acid exchanges (S1088N and D1291E) were detected (Wehage et al. 2002). Thus transcripts missing a part of exon 11 and/or the complete exon 27 may exist, although their relative abundance in blood leukocytes, HL60 cells and neutrophil granulocytes seemed to be rather low (Wehage et al. 2002; Perraud et al. 2003). Recombinant TRPM2 proteins carrying one or both deletions were overexpressed in HEK-293 cells and showed intriguing properties. In contrast to TRPM2 these variants did not respond to ADP-ribose indicating that both regions may be essential for channel activation. Most interestingly, while the C-terminal variant TRPM $2_{\Delta 1,292-1,325}$ lost its activity when exposed to ADP-ribose it retained the ability to gate in response to $\mathrm{H}_{2} \mathrm{O}_{2}$. This result is in line with the idea of an independent mechanism of TRPM2 activation by $\mathrm{H}_{2} \mathrm{O}_{2}$ and argues against a model in which NAD and its breakdown product ADP-ribose serve as diffusible mediators of oxidant-induced gating. However, the mechanisms underlying oxidant induced gating are under debate.

An additional splicing event has been detected in human bone marrow cells (Zhang et al. 2003a). Amplification of five partial cDNA fragments together covering the complete TRPM2 open reading frame detected an alternative splice acceptor site within intron 16 which encodes a stop codon. The deduced protein called TRPM2-S was predicted to contain the complete aminoterminus and the first two transmembrane spanning domains. Although it is not yet clear, if such a variant exists in vivo, its heterologous expression in HEK-293 cells gave further insights into the structure-function relationship of TRPM2. TRPM2-S coimmunoprecipitated with the long variant (TRPM2-L) and both variants seemed to be localized in the plasma membrane indicating that the aminoterminal part of TRPM2 is sufficient for protein-protein interaction. Expression of TRPM2-S suppressed $\mathrm{H}_{2} \mathrm{O}_{2}$ induced $\mathrm{Ca}^{2+}$ influx through TRPM2-L as well as oxidant induced cell death suggesting that this variant modulates TRPM2 channel activity and thereby providing an instrument through which cells can control their reaction to damaging oxidants.

\section{TRPM3}

TRPM3 is the closest relative of TRPM1. It is expressed in human kidney, testis and in the central nervous system but seemed to be absent in a variety of other human tissues (Grimm et al. 2003; Lee et al. 2003). Two publications described the cloning and functional properties of human TRPM3 (Grimm et al. 2003; Lee et al. 2003) but the data are inconsistent in view to molecular as well as functional aspects. Using 5' and 3' RACE strategies Grimm and colleagues identified three overlapping cDNA fragments from fetal brain and kidney together predicting a protein of 1,325 amino acid residues (Grimm et al. 2003). HEK-293 cells overexpressing TRPM $3_{1,325}$ showed constitutive $\mathrm{Ca}^{2+}$ entry, which was increased during treatment with hypotonic extracellular solutions. Electrophysiological analysis re- 
vealed that TRPM $3_{1,325}$ build nonselective $\mathrm{Ca}^{2+}$-permeable channels sensitive to the osmolarity of the extracellular medium (Grimm et al. 2003) and recent results indicated that TRPM $3_{1,325}$ can be activated by some sphingolipids (Grimm et al. 2005). TRPM3 $3_{1,325}$ seemed neither to be activated by phospholipase C (PLC) coupled receptors, $\mathrm{Ca}^{2+}$ store depletion (Grimm et al. 2003), fatty acids nor lipid metabolites from the phospholipase A2 pathway (Grimm et al. 2005). Due to its osmosensitivity and its presence in the kidney it has been suggested to play a role in renal $\mathrm{Ca}^{2+}$ homeostasis.

Another publication described a human protein of 1,554 amino acid residues designated TRPM3a (Lee et al. 2003). TRPM3a is in part identical to the protein described by Grimm and colleagues but differ in its amino- and carboxyterminus. Whereas 153 amino terminal residues present in TRPM $3_{1,325}$ are missing, TRPM3 a possess additional 382 amino acids at the C-terminal end. TRPM3a also showed constitutive $\mathrm{Ca}^{2+}$ entry when expressed in HEK293 cells but in contrast to TRPM $3_{1,325}$ this $\mathrm{Ca}^{2+}$ influx was augmented after stimulation of PLC coupled muscarinic receptors and after passive $\mathrm{Ca}^{2+}$ store depletion with thapsigargin. Northern blots showed TRPM3 transcripts of different length (Grimm et al. 2003; Lee et al. 2003) and five additional splice variants, TRPM3b-f, have been isolated from human kidney varying in size from 1,544 to 1,579 amino acid residues but none of them was identical to TRPM $3_{1,325}$. However, these data showed that TRPM3 is subject to frequent alternative splicing, implying that the functional differences described so far may be caused by the different primary structure of the variants. Hopefully, future comparative analysis of TRPM3 splice variants will illuminate their different functional behavior and will probably allow deeper insights into the functional domains of TRPM3.

\section{TRPM4/5}

Originally human TRPM4 has been described as a protein of 1,040 residues (Xu et al. 2001) but later it turned out, that this protein is a N-terminal truncated variant of a longer protein with 1,214 residues designated TRPM4b (Launay et al. 2002; Nilius et al. 2003). The human TRPM4 gene consists of 25 exons located at chromosome 19q13.33. $\mathrm{TRPM}_{1,040}$ (TRPMa) arises by splicing of exon 2 to an alternative splice acceptor site within exon $5 . \mathrm{Ca}^{2+}$ imaging experiments showed elevated $\mathrm{Ca}^{2+}$ influx in HEK-293 cells upon transient transfection of TRPM4a suggesting that this variant might build a $\mathrm{Ca}^{2+}$ influx pathway (Xu et al. 2001). This finding is somewhat surprising, since both variants share the same pore structures and extensive analysis characterized the longer variant TRPM4b as a $\mathrm{Ca}^{2+}$-activated but $\mathrm{Ca}^{2+}$-impermeable monovalent cation channel (Launay et al. 2002) whose activity is voltage-dependent (Hofmann et al. 2003; Nilius et al. 2003), blocked by $\mathrm{ATP}^{4-}$ (Nilius et al. 2004b) and modulated by decavanadate (Nilius et al. 2004a). Most interestingly, a mutant highly similar to TRPM4a coimmunoprecipitated with TRPM4b, had dominant negative effects on endogenous $\mathrm{Ca}^{2+}$-activated currents in lympho- cytes and modulated the oscillatory pattern of the intracellular $\mathrm{Ca}^{2+}$ concentration after T-cell activation (Launay et al. 2004). A third human variant TRPM4c has been cloned from prostate (Nilius et al. 2003). This variant starts with a truncated exon 11, which is alternatively spliced to exon 12 . It contains 678 amino acid residues starting at $\mathrm{Met}^{537}$ of TRPM4b. Although functional data are lacking, this variant might also build functional channels since it possesses the complete transmembrane region and a putative pore.

The mouse TRPM4 gene is localized in chromosome 7. B2 and displays a similar organization as the human gene with 25 exons. The mouse TRPM4b cDNA has been cloned from heart encoding a protein of 1,213 residues (Nilius et al. 2003 ) with $83 \%$ amino acid sequence identity to human TRPM4b. In addition, two shorter splice variants were identified which start at $\mathrm{Met}^{187}$. One of them displays 1,027 amino acids identical to TRPM4b. The other one is predicted to have 592 residues since an insertion in the transcript results in a shift of the reading frame and a premature stop. This variant lacks all transmembrane spanning domains and the carboxyterminus of TRPM4b. Two further splice variants have been reported (Murakami et al. 2003). Unfortunately they were also called TRPM4a (Acc. no. AB112658) and TRPM4b (AB112657) but should not to be confused with the above mentioned variants. Due to the strategy used for cloning of the transcripts, they both start within exon 16 and seem to be encoded by $5^{\prime}$ incomplete cDNA clones. Whereas AB112658 is identical to 488 carboxyterminal residues of TRPM4b starting at Met $^{726}$ within the first transmembrane segment, AB112657 lacks additional 66 residues of transmembrane segment 2 which are encoded by a part of exon 17. AB112658 still appeared to mediate $\mathrm{Ca}^{2+}$ entry whereas AB112657 was non-functional.

The closest relative of TRPM4 is TRPM5 (MTR1). Similar to TRPM4 it is a $\mathrm{Ca}^{2+}$-activated, monovalent selective cation channel (Hofmann et al. 2003; Liu and Liman 2003; Prawitt et al. 2003) which is involved in taste transduction (Perez et al. 2002; Zhang et al. 2003b). It has been initially identified in search for genes causal for Beckwith-Wiedemann syndrome (Prawitt et al. 2000) but so far it is not clear whether TRPM5 is involved in a disease. $4.5 \mathrm{~kb}$ TRPM5 transcripts with a putative open reading frame encoded by 24 exons are expressed in a variety of tissues. Alternative splicing leads to two predicted proteins of 872 or 1,165 residues (Prawitt et al. 2000). The longer form has been extensively studied in a variety of functional studies but the properties of the shorter one have not been studied so far.

\section{TRPM6/7}

TRPM6 (Chak2) and TRPM7 (Chak1, LTRPC7, TRPPLIK) are unique among ion channels because they contain a $\alpha$-kinase domain at their $\mathrm{C}$-terminus. The emerging roles of TRPM6/TRPM7 channel kinase signal transduction complexes are reviewed in an accompanying article of this issue (Gudermann et al. 2005). Both channels are thought to be involved in $\mathrm{Mg}^{2+}$ transport (reviewed by Montell 2003). They 
are known to build heteromultimeric structures (Chubanov et al. 2004) but they differ in their expression pattern. TRPM7 is abundant in various tissues (Runnels et al. 2001) but TRPM6 is mainly expressed in kidney and intestine, where it is responsible for $\mathrm{Mg}^{2+}$ (re)absorption (Schlingmann et al. 2002; Walder et al. 2002; Voets et al. 2004b). TRPM6 gives an excellent example for the physiological importance of correct mRNA processing: As reported by two independent groups (Schlingmann et al. 2002; Walder et al. 2002) several mutations leading to missplicing of TRPM6 transcripts are associated with an autosomal recessive hereditary disorder called hypomagnesemia with secondary hypocalcemia (HSH). This disease is characterized by very low magnesium and calcium serum levels and HSH-patients suffer from generalized convolutions, muscle spasm, and tetany. These findings also document the first example that TRPM dysfunction is responsible for a human disease. In addition, multiple TR PM6 mRNA isoforms encoding proteins
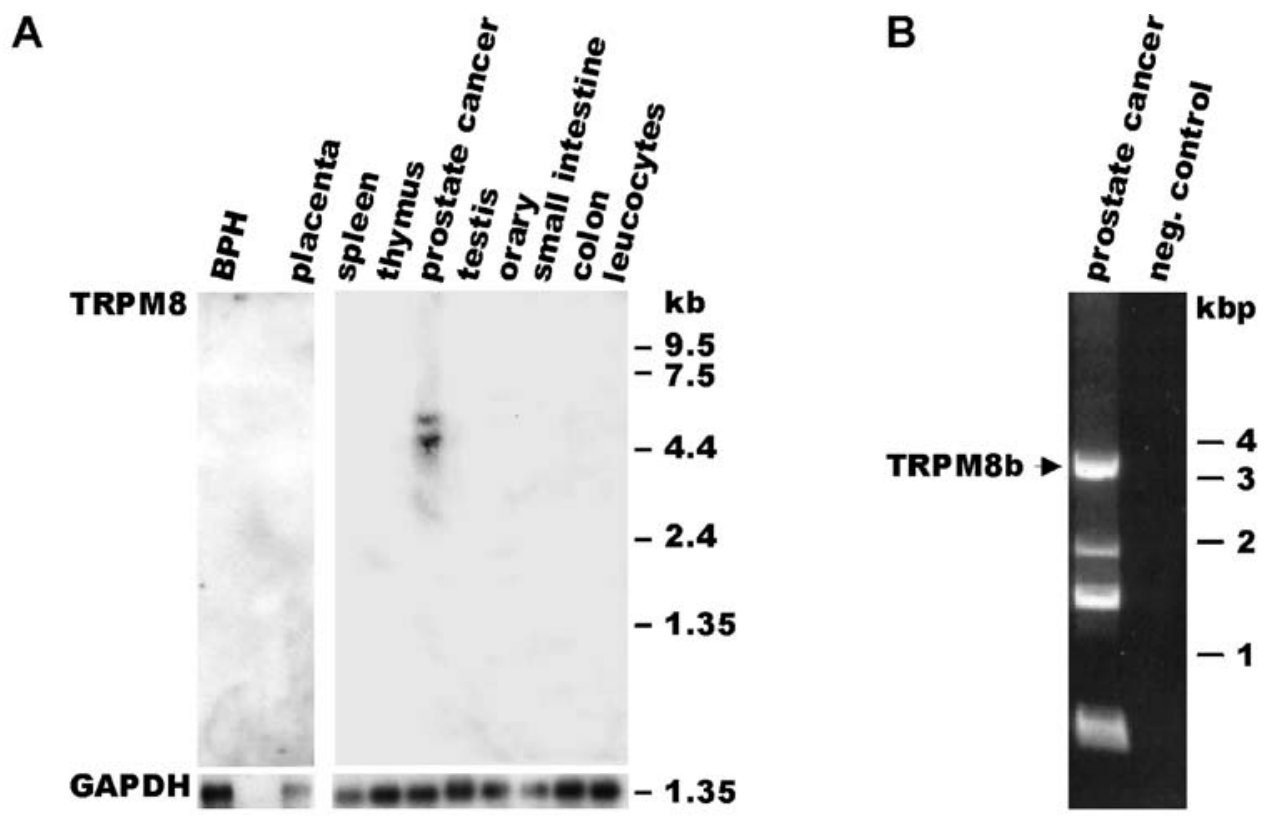

C
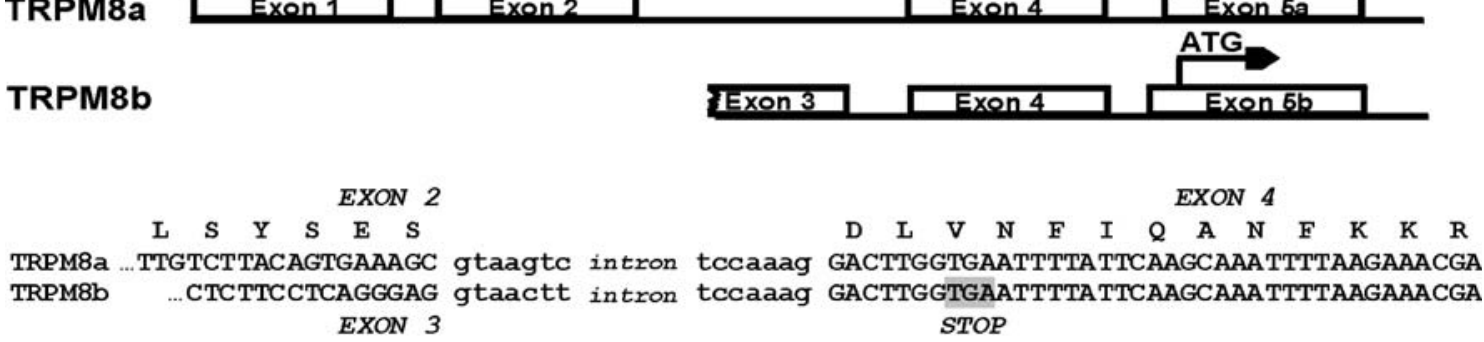

$\begin{array}{llllllllllll}\text { E } & \text { C } & \text { V } & \text { F } & \text { F } & \text { T } & \text { K } & \text { D } & \text { S } & \text { K } & \text { A } & \text { T }\end{array}$

TRPM8a GAATGTGTCTTCTTTACCAAAGATTCCAAGGCCAC gtaagct intron taagcag gctcaatgaaatccttccttcct TRPM8b GAATGTGTCTTCTTTACCAAAGATTCCAAGGCCAC gtaagct intron taagcag GCTCAATGAAATCCTTCCTTCCT $\begin{array}{llllllllll}M & \text { K } & \text { S } & \text { F } & \text { L } & \text { P }\end{array}$

EXON 5 a

$\begin{array}{lllllllll}E & N & V & C & K & C & G & Y\end{array}$

TRPM8a gtccacaccatcgtgcttatcag G GAGAATGTGTGCAAGTGTGGCTAT... TRPM8b GTCCACACCATCGTGCTTATCAGG GAGAATGTGTGCAAGTGTGGCTAT.

$\begin{array}{llllllllllllllll}\mathrm{V} & \mathrm{H} & \mathrm{T} & \mathrm{I} & \mathrm{V} & \mathrm{L} & \mathrm{I} & \mathrm{R} & \mathrm{E} & \mathrm{N} & \mathrm{V} & \mathrm{C} & \mathrm{K} & \mathrm{C} & \mathrm{G} & \mathrm{Y} . .\end{array}$

Fig. 3 Identification of TRPM8 splice variants in human prostate cancer. a Northern blot analysis identifies expression of different TRPM8 transcripts in prostate cancer, but not in benign prostate tissue $(B P H)$. Lower panel shows control hybridizations of the same blots with the glyceraldehyde-3-phosphate dehydrogenase $(G A P D H)$ cDNA. b RT-PCR amplification of TRPM8b fragments. The longest fragment (arrow) encodes the complete TRPM8b cDNA. c Schematic structure of a part of the TRPM8 gene. The lower panel shows nu- cleotide sequences of exons (upper case) 2, 3, 4, 5a, and 5b including intron borders (lower case) and the encoded amino acid sequences of TRPM8a and TRPM8b. Alternative splice acceptor sites ( $a g$ ) are marked, a stop codon in frame to the translation initiation site of TRPM8b is highlighted in gray. Nucleotides of a TRPM8b specific primer are underlined. The sequence of TRPM8b has been deposited in the GeneBank database. 
of 569-2,022 residues were identified (Chubanov et al. 2004). TRPM6a, TRPM6b and TRPM6c differ only in their aminoterminal end and derive from alternative use of exons $1 \mathrm{a}, 1 \mathrm{~b}$, and $1 \mathrm{c}$ located within a 700 -bp region on chromosome 9q22. Obviously the TRPM6 gene harbors a promoter with alternative transcription initiation sites. These variants seemed to have individual expression patterns. TRPM6a and TRPM6b are present in kidney, testis and cells derived from lung but TRPM6c is absent in kidney cells. Furthermore, three splice variants lacking the transmembrane region were described in the same manuscript (Chubanov et al. 2004). They were called M6-kinases, since their aminoterminus is still homologous to melastatin and their carboxyterminus carries the kinase domain. The identification of these variants implies that the function of the kinase domain is not restricted to ion channel modulation. Finally, splicing in exon 36 has been reported, leading to a premature stop codon and a C-terminal truncation. The resulting variant was designated TRPM6t since it seems to be specifically expressed in testis (Chubanov et al. 2004).

\section{TRPM8}

TRPM8 (formerly CMR1 or Trp-p8) comprises 1,104 amino acids and is expressed in a subset of sensory neurons which can be stimulated by cold temperatures (McKemy et al. 2002; Peier et al. 2002). TRPM8 also responds to menthol and icilin and shows voltage dependent gating but a link between temperature sensitivity and voltage dependence is controversially discussed (Voets et al. 2004a; Brauchi et al. 2004). TRPM 8 is expressed in malign prostate cancer cells (Tsavaler et al. 2001) but in benign prostate hyperplasia (BPH) TRPM8 transcripts are not detectable (Fig. 3a). The human TRPM8 gene consists of at least 27 exons located at chromosome $2 \mathrm{q} 37$. Several human expressed sequence tags (EST CA394721, BX283818, BE274448, BE390627) encode an altered aminoterminus of TRPM8. We identified a splice variant of TRPM8 called TRPM8b, which differ from the 1,104 aa protein (now defined as TRPM8a) in its aminoterminus (Fig. 3b, c). We used a primer specific for TRPM $8 b$ deduced from the exon $5 b$ in combination with a primer located downstream of the reading frame of both variants to amplify 3,165-bp fragments from prostate cancer (Fig. 3b, arrow). Amplification products were subcloned and sequencing identified TRPM8b with 1,054 amino acids in length. The shorter amplification products (Fig. 3b) are not yet characterized but might encode further TRPM8 splice forms. Figure 3c shows the part of the TRPM8 gene which encodes the alternative aminotermini of TRPM8a and TRPM8b. Exon 1 and exon 3 are non-coding. Translation of TRPM8a starts in exon 2, the one of TRPM8b in exon 5b. In TRPM8a exons 1, 2, 4, and 5a are fused. In TRPM $8 b$ exons 3 and 4 are fused. An alternative splice acceptor site within the following intron leads to an extension of exon 5 (exon 5 b) by 47 nucleotides. In the resulting transcript of variant $b$ the first ATG is in frame to an upstream located stop codon (Fig. 3c). Starting with the amino acid sequence ENV in exon 5 the reading frames of both proteins are identical. The functional significance of the new variant in prostate cancer cells is still unclear. However, TRPM8b might serve as a dominant negative regulator of TRPM8a similar as suggested for amino- and carboxyterminal truncated variants of TRPM4 (Launay et al. 2004), TRPM2 (Zhang et al. 2003a), and TRPM1 (Xu et al. 2001).

\section{Conclusions}

Genomic database resources have largely facilitated the identification of most of the TRP genes in the last 10 years by similarity screens. However, because transcriptional regulation and post-transcriptional mRNA processing are hardly predictable from genomic information, we need now to decipher the TRP transcriptome. Two major aspects have to be considered: First, comparative analysis of different variants can help us understand structure-function relationships of TRP channel proteins. Second, as some examples already show, TRP variants are differentially expressed and might serve particular functions in different cell types. Thus, to understand the physiological role and the molecular identity of native TRP channels it is necessary to determine the subset of TRP variants expressed in a specific kind of cell. Hitherto, we know little about alternative TRP transcripts. Some variants are already identified but there are presumably more. Some of them may only be accidental and with unknown significance. Therefore, future studies should initially show if alternative transcripts are abundant and if the encoded proteins are really present in the cell before we draw conclusions about their physiological relevance.

\section{References}

Antoniotti S, Lovisolo D, Fiorio PA, Munaron L (2002) Expression and functional role of bTRPC1 channels in native endothelial cells. FEBS Lett 510:189-195

Berg LP, Shamsher MK, El DS, Kakkar VV, Authi KS (1997) Expression of human TRPC genes in the megakaryocytic cell lines MEG01, DAMI and HEL. FEBS Lett 403:83-86

Brauchi S, Orio P, Latorre R (2004) Clues to understanding cold sensation: thermodynamics and electrophysiological analysis of the cold receptor TRPM8. Proc Natl Acad Sci USA 101:1549415499

Chang AS, Chang SM, Garcia RL, Schilling WP (1997) Concomitant and hormonally regulated expression of trp genes in bovine aortic endothelial cells. FEBS Lett 415:335-340

Chu X, Cheung JY, Barber DL, Birnbaumer L, Rothblum LI, Conrad K, Abrasonis V, Chan YM, Stahl R, Carey DJ, Miller BA (2002) Erythropoietin modulates calcium influx through TRPC2. J Biol Chem 277:34375-34382

Chu X, Tong Q, Cheung JY, Wozney J, Conrad K, Mazack V, Zhang W, Stahl R, Barber DL, Miller BA (2004) Interaction of TRPC2 and TRPC6 in erythropoietin modulation of calcium influx. J Biol Chem 279:10514-10522

Chubanov V, Waldegger S, Schnitzler M, Vitzthum H, Sassen MC, Seyberth HW, Konrad M, Gudermann T (2004) Disruption of TRPM6/TRPM7 complex formation by a mutation in the TRPM6 gene causes hypomagnesemia with secondary hypocalcemia. Proc Natl Acad Sci USA 101:2894-2899

Deeds J, Cronin F, Duncan LM (2000) Patterns of melastatin mRNA expression in melanocytic tumors. Human Pathol 31:1346-1356 
Den Dekker E, Molin DG, Breikers G, van Oerle R, Akkerman JW, van Eys GJ, Heemskerk JW (2001) Expression of transient receptor potential mRNA isoforms and $\mathrm{Ca}(2+)$ influx in differentiating human stem cells and platelets. Biochim Biophys Acta 1539:243-255

Duncan LM, Deeds J, Hunter J, Shao J, Holmgren LM, Woolf EA, Tepper RI, Shyjan AW (1998) Down-regulation of the novel gene melastatin correlates with potential for melanoma metastasis. Cancer Res 58:1515-1520

Duncan LM, Deeds J, Cronin FE, Donovan M, Sober AJ, Kauffman M, McCarthy JJ (2001) Melastatin expression and prognosis in cutaneous malignant melanoma. J Clin Oncol 19:568-576

Fang D, Setaluri V (2000) Expression and up-regulation of alternatively spliced transcripts of melastatin, a melanoma metastasis-related gene, in human melanoma cells. Biochem Biophys Res Commun 279:53-61

Fleig A, Penner R (2004) The TRPM ion channel subfamily: molecular, biophysical and functional features. Trends Pharmacol Sci 25:633-639

Freichel M, Wissenbach U, Philipp S, Flockerzi V (1998) Alternative splicing and tissue specific expression of the 5 ' truncated bCCE 1 variant bCCE $1_{\Delta 514}$. FEBS Lett 422:354-358

Grimm CM, Kraft R, Sauerbruch S, Schultz G, Harteneck C (2003) Molecular and functional characterization of the melastatinrelated cation channel TRPM3. J Biol Chem 278:21493-21501

Grimm C, Kraft R, Schultz G, Harteneck C (2005) Activation of the melastatin-related cation channel TRPM3 by D-erythro-sphingosine. Mol Pharmacol 67:798-805

Gudermann T, Chubanov V, Mederos y Schnitzler M, Wäring J, Plank A (2005) Emerging roles of TRPM6/TRPM7 channel kinase signal transduction complexes. Naunyn-Schmiedebergs Arch Pharmacol (in press)

Hara Y, Wakamori M, Ishii M, Maeno E, Nishida M, Yoshida T, Yamada H, Shimizu S, Mori E, Kudoh J, Shimizu N, Kurose H, Okada Y, Imoto K, Mori Y (2002) LTRPC2 Ca2+-permeable channel activated by changes in redox status confers susceptibility to cell death. Mol Cell 9:163-173

Harteneck C (2005) Function and pharmacology of TRPM cation channel. Naunyn-Schmiedebergs Arch Pharmacol (in press)

Heiner I, Radukina N, Eisfeld J, Kühn A, Lueckhoff A (2005) Regulation of TRPM2 channels in neutrophil granulocytes by ADP-ribose: a promising pharmacological target. NaunynSchmiedebergs Arch Pharmacol (in press)

Hofmann T, Schaefer M, Schultz G, Gudermann T (2000) Cloning, expression and subcellular localization of two novel splice variants of mouse transient receptor potential channel 2. Biochem J 351:115-122

Hofmann T, Chubanov V, Gudermann T, Montell C (2003) TRPM5 is a voltage-modulated and $\mathrm{Ca}^{2+}$-activated monovalent selective cation channel. Curr Biol 13:1153-1158

Hunter JJ, Shao J, Smutko JS, Dussault BJ, Nagle DL, Woolf EA, Holmgren LM, Moore KJ, Shyjan AW (1998) Chromosomal localization and genomic characterization of the mouse melastatin gene (Mlsn1). Genomics 54:116-123

Launay P, Fleig A, Perraud AL, Scharenberg AM, Penner R, Kinet JP (2002) TRPM4 is a $\mathrm{Ca}^{2+}$-activated nonselective cation channel mediating cell membrane depolarization. Cell 109:397-407

Launay P, Cheng H, Srivatsan S, Penner R, Fleig A, Kinet JP (2004) TRPM4 regulates calcium oscillations after $\mathrm{T}$ cell activation. Science 306:1374-1377

Lee N, Chen J, Wu S, Sun L, Huang M, Levesque PC, Rich A, Feder JN, Gray KR, Lin JH, Janovitz EB, Blanar MA (2003) Expression and characterization of human transient receptor potential melastatin 3 (hTRPM3). J Biol Chem 278:2089020897

Liu D, Liman ER (2003) Intracellular Ca2+ and the phospholipid PIP2 regulate the taste transduction ion channel TRPM5. Proc Natl Acad Sci USA 100:15160-15165

McKemy DD, Neuhausser WM, Julius D (2002) Identification of a cold receptor reveals a general role for TRP channels in thermosensation. Nature 416:52-58
Mery L, Magnino F, Schmidt K, Krause KH, Dufour JF (2001) Alternative splice variants of hTrp4 differentially interact with the C-terminal portion of the inositol 1,4,5-trisphosphate receptors. FEBS Lett 487:377-383

Miller AJ, Du J, Rowan S, Hershey CL, Widlund HR, Fisher DE (2004) Transcriptional regulation of the melanoma prognostic marker melastatin (TRPM1) by MITF in melanocytes and melanoma. Cancer Res 64:509-516

Montell C (2003) $\mathrm{Mg}^{2+}$ homeostasis: the $\mathrm{Mg}^{2+}$ nificent TRPM chanzymes. Curr Biol 13:R799-R801

Montell C, Birnbaumer L, Flockerzi V, Bindels RJ, Bruford EA, Caterina MJ, Clapham DE, Harteneck C, Heller S, Julius D, Kojima I, Mori Y, Penner R, Prawitt D, Scharenberg AM, Schultz G, Shimizu N, Zhu MX (2002) A unified nomenclature for the superfamily of TRP cation channels. Mol Cell 9:229-231

Murakami M, Xu F, Miyoshi I, Sato E, Ono K, Iijima T (2003) Identification and characterization of the murine TRPM4 channel. Biochem Biophys Res Commun 307:522-528

Nagamine K, Kudoh J, Minoshima S, Kawasaki K, Asakawa S, Ito F, Shimizu N (1998) Molecular cloning of a novel putative Ca2+ channel protein (TRPC7 highly expressed in brain). Genomics $54: 124-131$

Niemeyer BA (2005) Structure-function analysis of TRPV channels. Naunyn-Schmiedebergs Arch Pharmacol (in press)

Nilius B, Prenen J, Droogmans G, Voets T, Vennekens R, Freichel M, Wissenbach U, Flockerzi V (2003) Voltage dependence of the $\mathrm{Ca}^{2+}$-activated cation channel TRPM4. J Biol Chem 278:3081330820

Nilius B, Prenen J, Janssens A, Voets T, Droogmans G (2004a) Decavanadate modulates gating of TRPM4 cation channels. J Physiol 560:753-765

Nilius B, Prenen J, Voets T, Droogmans G (2004b) Intracellular nucleotides and polyamines inhibit the $\mathrm{Ca} 2+$-activated cation channel TRPM4b. Pflügers Arch 448:70-75

Ohki G, Miyoshi T, Murata M, Ishibashi K, Imai M, Suzuki M (2000) A calcium-activated cation current by an alternatively spliced form of Trp3 in the heart. J Biol Chem 275:39055-39060

Peier AM, Reeve AJ, Andersson DA, Moqrich A, Earley TJ, Hergarden AC, Story GM, Colley S, Hogenesch JB, McIntyre P, Bevan S, Patapoutian A (2002) A heat-sensitive TRP channel expressed in keratinocytes. Science 296:2046-2049

Perez CA, Huang L, Rong M, Kozak JA, Preuss AK, Zhang H, Max M, Margolskee RF (2002) A transient receptor potential channel expressed in taste receptor cells. Nat Neurosci 5:1169-1176

Perraud AL, Fleig A, Dunn CA, Bagley LA, Launay P, Schmitz C, Stokes AJ, Zhu Q, Bessman MJ, Penner R, Kinet JP, Scharenberg AM (2001) ADP-ribose gating of the calcium-permeable LTRPC2 channel revealed by Nudix motif homology. Nature 411:595-599

Perraud AL, Schmitz C, Scharenberg AM (2003) TRPM2 Ca2+ permeable cation channels: from gene to biological function. Cell Calcium 33:519-531

Perraud AL, Knowles HM, Schmitz C (2004) Novel aspects of signaling and ion-homeostasis regulation in immunocytes. The TRPM ion channels and their potential role in modulating the immune response. Mol Immunol 41:657-673

Philipp S, Trost C, Warnat J, Rautmann J, Himmerkus N, Schroth G, Kretz O, Nastainczyk W, Cavalie A, Hoth M, Flockerzi V (2000) TRP4 (CCE1) protein is part of native calcium release-activated $\mathrm{Ca}^{2+}$-like channel in adrenal cells. J Biol Chem 275:2396023972

Prawitt D, Enklaar T, Klemm G, Gartner B, Spangenberg C, Winterpacht A, Higgins M, Pelletier J, Zabel B (2000) Identification and characterization of MTR1, a novel gene with homology to melastatin (MLSN1) and the trp gene family located in the BWS-WT2 critical region on chromosome 11p15.5 and showing allele-specific expression. Hum Mol Genet 9:203-216

Prawitt D, Monteilh-Zoller MK, Brixel L, Spangenberg C, Zabel B, Fleig A, Penner R (2003) TRPM5 is a transient Ca2+-activated cation channel responding to rapid changes in $[\mathrm{Ca} 2+] \mathrm{I}$. Proc Natl Acad Sci USA 100:15166-15171 
Qian F, Huang P, Ma L, Kuznetsov A, Tamarina N, Philipson LH (2002) TRP genes: candidates for nonselective cation channels and store-operated channels in insulin-secreting cells. Diabetes 51 [Suppl 1]:S183-S189

Runnels LW, Yue L, Clapham DE (2001) TRP-PLIK, a bifunctional protein with kinase and ion channel activities. Science 291: 1043-1047

Sakura H, Ashcroft FM (1997) Identification of four trp 1 gene variants murine pancreatic beta-cells. Diabetologia 40:528-532

Sanchez JF, Krause JE, Cortright DN (2001) The distribution and regulation of vanilloid receptor VR1 and VR1 5' splice variant RNA expression in rat. Neuroscience 107:373-381

Sano Y, Inamura K, Miyake A, Mochizuki S, Yokoi H, Matsushime H, Furuichi K (2001) Immunocyte Ca2+ influx system mediated by LTRPC2. Science 293:1327-1330

Satoh E, Ono K, Xu F, Iijima T (2002) Cloning and functional expression of a novel splice variant of rat TRPC4. Circ J 66:954958

Schaefer M, Plant TD, Stresow N, Albrecht N, Schultz G (2002) Functional differences between TRPC4 splice variants. J Biol Chem 277:3752-3759

Schlingmann KP, Weber S, Peters M, Niemann NL, Vitzthum H, Klingel K, Kratz M, Haddad E, Ristoff E, Dinour D, Syrrou M, Nielsen S, Sassen M, Waldegger S, Seyberth HW, Konrad M (2002) Hypomagnesemia with secondary hypocalcemia is caused by mutations in TRPM6, a new member of the TRPM gene family. Nat Genet 31:166-170

Schumacher MA, Moff I, Sudanagunta SP, Levine JD (2000) Molecular cloning of an N-terminal splice variant of the capsaicin receptor. Loss of N-terminal domain suggests functional divergence among capsaicin receptor subtypes. J Biol Chem 275:2756-2762

Tsavaler L, Shapero MH, Morkowski S, Laus R (2001) Trp-p8, a novel prostate-specific gene, is up-regulated in prostate cancer and other malignancies and shares high homology with transient receptor potential calcium channel proteins. Cancer Res 61:3760-3769

Vannier B, Peyton M, Boulay G, Brown D, Qin N, Jiang M, Zhu X, Birnbaumer L (1999) Mouse trp2, the homologue of the human trpc2 pseudogene, encodes mTrp2, a store depletion-activated capacitative $\mathrm{Ca} 2+$ entry channel. Proc Natl Acad Sci USA 96:2060-2064

Voets T, Droogmans G, Wissenbach U, Janssens A, Flockerzi V, Nilius B (2004a) The principle of temperature-dependent gating in cold- and heat-sensitive TRP channels. Nature 430:748-754

Voets T, Nilius B, Hoefs S, van der Kemp AW, Droogmans G, Bindels RJ, Hoenderop JG (2004b) TRPM6 forms the $\mathrm{Mg}^{2+}$ influx channel involved in intestinal and renal $\mathrm{Mg} 2+$ absorption. J Biol Chem 279:19-25

Walder RY, Landau D, Meyer P, Shalev H, Tsolia M, Borochowitz Z, Boettger MB, Beck GE, Englehardt RK, Carmi R, Sheffield VC (2002) Mutation of TRPM6 causes familial hypomagnesemia with secondary hypocalcemia. Nat Genet 31:171-174
Walker RL, Hume JR, Horowitz B (2001) Differential expression and alternative splicing of TRP channel genes in smooth muscles. Am J Physiol Cell Physiol 280:C1184-C1192

Walker RL, Koh SD, Sergeant GP, Sanders KM, Horowitz B (2002) TRPC4 currents have properties similar to the pacemaker current in interstitial cells of Cajal. Am J Physiol Cell Physiol 283: C1637-C1645

Wang C, Hu HZ, Colton CK, Wood JD, Zhu MX (2004) An alternative splicing product of the murine trpv1 gene dominant negatively modulates the activity of TRPV1 channels. J Biol Chem 279:37423-37430

Wang W, O'Connell B, Dykeman R, Sakai T, Delporte C, Swaim W, Zhu X, Birnbaumer L, Ambudkar IS (1999) Cloning of Trp1 beta isoform from rat brain: immunodetection and localization of the endogenous Trp1 protein. Am J Physiol 276:C969-C979

Wehage E, Eisfeld J, Heiner I, Jungling E, Zitt C, Luckhoff A (2002) Activation of the cation channel long transient receptor potential channel 2 (LTRPC2) by hydrogen peroxide. A splice variant reveals a mode of activation independent of ADP-ribose. J Biol Chem 277:23150-23156

Wissenbach U, Schroth G, Philipp S, Flockerzi V (1998) Structure and mRNA expression of a bovine trp homologue related to mammalian trp2 transcripts. FEBS Lett 429:61-66

$\mathrm{Xu} \mathrm{XZ,} \mathrm{Moebius} \mathrm{F,} \mathrm{Gill} \mathrm{DL,} \mathrm{Montell} \mathrm{C} \mathrm{(2001)} \mathrm{Regulation} \mathrm{of}$ melastatin, a TRP-related protein, through interaction with a cytoplasmic isoform. Proc Natl Acad Sci USA 98:10692-10697

Xue Q, Yu Y, Trilk SL, Jong BE, Schumacher MA (2001) The genomic organization of the gene encoding the vanilloid receptor: evidence for multiple splice variants. Genomics 76:14-20

Yang M, Gupta A, Shlykov SG, Corrigan R, Tsujimoto S, Sanborn BM (2002) Multiple Trp isoforms implicated in capacitative calcium entry are expressed in human pregnant myometrium and myometrial cells. Biol Reprod 67:988-994

Yildirim E, Dietrich A, Birnbaumer L (2003) The mouse C-type transient receptor potential 2 (TRPC2) channel: alternative splicing and calmodulin binding to its $\mathrm{N}$ terminus. Proc Natl Acad Sci USA 100:2220-2225

Zhang L, Saffen D (2001) Muscarinic acetylcholine receptor regulation of TRP6 Ca2 + channel isoforms. Molecular structures and functional characterization. J Biol Chem 276:13331-13339

Zhang W, Chu X, Tong Q, Cheung JY, Conrad K, Masker K, Miller BA (2003a) A novel TRPM2 isoform inhibits calcium influx and susceptibility to cell death. J Biol Chem 278:16222-16229

Zhang Y, Hoon MA, Chandrashekar J, Mueller KL, Cook B, Wu D, Zuker CS, Ryba NJ (2003b) Coding of sweet, bitter, and umami tastes: different receptor cells sharing similar signaling pathways. Cell 112:293-301

Zhiqi S, Soltani MH, Bhat KM, Sangha N, Fang D, Hunter JJ, Setaluri V (2004) Human melastatin 1 (TRPM1) is regulated by MITF and produces multiple polypeptide isoforms in melanocytes and melanoma. Melanoma Res 14:509-516 